\title{
Role Conflict and its effect on Middle Class Working Women of India
}

\author{
${ }^{1}$ Somya Pandit, ${ }^{2}$ Shobha Upadhaya \\ ${ }^{1}$ Sr.Lecturer, ${ }^{2}$ Lecturer Management Dept. SRMGPC Lucknow India
}

\begin{abstract}
Women of India have marked their significant presence in the world in various fields. They have been given the status of power and prestige in India. With the emergence of middle class, women of this segment have developed to a great extent. They form the major female work force of India. In various sectors and fields of work, these middle class women have majorly been employed.

Conflicts arise when one or the other party is not able to reach to an agreement. It is the stage where disagreement crops up. Role conflict is an outcome of conflicts in number of roles performed by an individual. Middle working women are major victims of this issue. They perform number of roles through their lives to an extent that they fail to retain their own identity. A major problem of conflict and identity crises crops up.
\end{abstract}

Key words: Middle class working women of India, Role conflict, Types of role conflict faced by them, Measures to overcome the role conflict.

\section{Introduction}

In the present scenario there are lots of responsibilities for the working women as she has to manage the job as well as she has to handle her spouse family \& her parents. There are lots of conflict arises in managing the above responsibility. Sometimes these types of conflict create a challenging situation for women. This qualitative study investigated those marriages, particularly the unique internal and external elements that impact communication and conflict within family. Most people who have ever been married would probably wholeheartedly agree that all marriages include conflict (Tallman \& Hsiao, 2004). As two individuals merge their lives into one, problems erupt. Both parties carry their unique experiences, personalities, and cultures with In today's society, the face of intimate relationships is changing. Deep bonds between persons of diverse cultures are becoming more common and intercultural marriages are on the rise (Waldman \& Rubalcava, 2005; Frame, 2004).As two culturally diverse individuals who independently possess distinct national cultures that impact their individual worldviews, values, and personal philosophies. For the purpose of this study, culture is defined as -inclusive of common ethnic, linguistic, racial, and historical backgrounds $\square$ (Kim, 2008, p. 360). Interpersonal conflict is defined as a situation where in the two individuals are interdependent; they possess opposing objectives which have the power to negatively impact the relationship if not resolved; it is essential that the differences be settled as quickly as possible (Cahn \& Abigail, 2007). Conflict has negative connotations in many contexts; however conflict can produce positive results.

\section{Role Conflict}

"Role conflict is a conflict among the roles corresponding to two or more statuses." We experience role conflict when we find ourselves pulled in various directions as we try to respond to the many statuses we hold Role conflict can be something that can be for either a short period of time, or a long period of time, and it can also connected to situational experiences.

"An example of role conflict would be a husband and father who is also Chief of Police. If a tornado strikes the small town he is living in, the man has to decide if he should go home and be with his family and fulfill the role of being a good husband and father or remain and fulfill the duties of a "good" Chief of Police because the whole town needs his expertise.

\section{Types of role conflict faced by Middle Class working Women of India}

An Indian Working woman performs many roles throughout her life like any other women of any nationality. Issues and conflicts crop up because in her conquest to justify every role in her life she fails to restore her identity.

- Role conflict as an growing daughter-India is male dominant country. Rules policies, schemes are framed according to the gender .Religious and societal norms also vary with the gender. Our daughter are sent to school, colleges and other eminent places which could instill in them good values and education .Mean while they are taught household chores which is very much unlikely to their male sibling. Their male counterpart as young student has to study and play whereas they do many other things. This is a good concept until and unless this does not create conflict in their minds. They treat their brother or a male friend 
as their equivalent but the number of jobs which they perform is more than their male counterparts. This creates a mental turmoil on a very initial level.

- Role conflict as working girl-When they grow up and pursue their careers arise major conflict. Their career choice is not their sole decision but of their family members which is not the case with most of the boys. If they perform well at their work place they emerge as mature girl but again right to decide the groom for themselves is not majorly granted. She may be an outstanding employee but her martial decisions are not in her hand. This situation occurs in most of the middle class homes where girls are working. Such incidences put a question mark on their maturity level and the trust their parents have on them. Conflict arise as at one place they are well groomed and efficient person and on the other they are not even treated mature enough to decide their husbands.

- Role conflict as a wife (home maker) - After her marriage which is well versed with dowry her responsibilities and duties get multiplies but her rights are hardly acknowledged. After huge dowry and no persuasion in her career life creates a unhealthy state of mind. Her own parents leave her to destiny. She is taught to sacrifice most of the time .After having best of the qualifications her identity ceases to being an homemaker if it is not by her own choice. She gets almost no appreciation or regard for being what she is. It is a rare case when groom or his family members are supportive enough to help her maintain a balance in her personal and professional life. All of a sudden her male counterpart whom she thinks was equivalent to her becomes her destiny maker .Conflicts arise, as there are multiple roles of wife, mother daughter-in law etc and each of them is very demanding .In order to perform every role she fails to retail her identity. She forgets her education, her dreams for the sake of family but hardly any of us acknowledge her efforts.

- Role conflict as a working married woman- It is always said that behind a successful man there is a woman who is most of the times his wife .But how many times we have heard that behind a successful woman is her husband. It is a very rare case in India at least.At times she becomes a victim of jealous husband if her professional life is better than him. Just imagine a situation where both husband and wife enter house at $7 \mathrm{pm}$. Both are equally tired but wife is now occupied with the house hold chores of the family whereas husband rests in front of tv. Food, clothing, children, in laws etc all waiting to be dealt with. She sleeps last and gets up the first. It's very rare that she receives any assistance from family members .On top of that she might be the best of employees but she can never make any family member realize this.

A girl was brought up taught and married to perform endless duties for others. Imagine for yourself. You along with your parents dream of becoming an IAS officer. With God's grace and hard work your dream comes true. Parents give dowry and get her married and then her life is occupied with other's needs, their requirements etc. A girl who had smile in heart and dreams in eyes has now become a machine. Her multiple roles has reduced her role in her life.

\section{Measures to reduce the fatal effects of role conflict faced by Middle Class working Women of India-}

- Support from her parents-A plants which strong roots is capable of striving through the tough weather. Parents should pay a lot more attention in their daughter's upbringing. They should guide her through the ups and downs which she would meet in her life. As parents they must trust her and let her take her own decisions where ever required lot of confidence and feeling of selflessness must be instilled in her so that she might not take the changes in her life as conflicts.

- Support from her in laws and husband-They must understand that the society is made from the people living in it. If girls are imbibed with good educational values then this is futile for their family as well .They must never ask for dowry and even support her in house hold chores Her proficiencies in both personal and professional life must be appreciated .Such measures will too an extent reduce the level of role conflict.

- Social interaction with other females of her age group-On e must have heard that woman is worst enemies and best friends. Social interaction, guidance from other mature women etc help in reducing the major conflicts. Through the experiences of other much settled women, one can take help in resolving many issues.

- Self Help-There is no help better than self help .If you are in problem or any conflicting situation one must not leave to destiny or submit it to time instead fight for it .Arrogance or violence has never fetch anything, it is the wit and practical attitude which saves us from hardships. It is very important to have good communication skill and decent level of perseverance. Conflicts can be resolved without breaking or harming relations.

\section{Conclusion}

A woman is the world in itself. Her beauty, care knowledge etc has no substitute in the world .It is important to realize that we as woman have immense power. This power must be used efficiently. No family runs without the sacrifices or adjustments made by the women. But they must be limited in extent .She should not feel incomplete or a mere worker. Her own individual identity should never cease to exist. Husband, parents etc must realize her worth in their life and take good care of her .Middle class families make the most of the 
adjustment in life but these adjustments should not become the part of any ones identity. Multiplies roles, deadlines, family pressure are part of today's life. But these hurdles are becoming rocks in path of healthy life. In it vital to cultivate necessary reforms in today's lifestyles for a better and healthier tomorrow.

\section{References}

[1] Role conflict in working women, Chetna Pub, Organization Behavior, L.M.Prasad

[2] Organizational Behavior and theory, V.S.P.Rao

[3] transition.usaid.gov/.../conflict/.../cmm_women_and_conflict en.wikipedia.org/wiki/Gender_role

[4] shodhganga.inflibnet.ac.in/bitstream/.../05_chapter\%201.pdf 